\title{
Functional status of reproductive system under treatment of silver nanoparticles in female mice
}

\author{
Alina P. Lytvynenko ${ }^{1}$, Ludmila S. Rieznichenko², Valentine A. Sribna ${ }^{1}$, Maria I. Stupchuk ${ }^{1}$, \\ Nataliya G. Grushka ${ }^{1}$, Alena A. Shepel ${ }^{1}$, Tetyana Yu. Voznesenska ${ }^{1}$, Taras V. Blashkiv ${ }^{1 *}$, \\ Oksana N. Kaleynykova ${ }^{1}$
}

\begin{abstract}
${ }^{1}$ Department of Immunophysiology O. O. Bogomoletz Instytute of Physiology National Academy of Sciences of Ukraine, Kyiv, Ukraine

${ }^{2}$ Department of Colloidal Technology of Natural Systems, F. D. Ovcharenko Institute of Biocolloidal Chemistry National Academy of Sciences of Ukraine, Kyiv, Ukraine
\end{abstract}

Received: 27 February 2017

Accepted: 31 March 2017

\section{*Correspondence:}

Dr. Taras V. Blashkiv,

E-mail: tblashkiv@gmail.com

Copyright: ( ) the author(s), publisher and licensee Medip Academy. This is an open-access article distributed under the terms of the Creative Commons Attribution Non-Commercial License, which permits unrestricted non-commercial use, distribution, and reproduction in any medium, provided the original work is properly cited.

\begin{abstract}
Background: The use of silver nanoparticles (AgNP) has increased very significantly in recent years the work in science is currently on focused on assessing human health and environmental risks of nanotechnology. The aim of the present study was to estimate the functional status of the female reproductive system in mice under condition of the intravenous treatment of silver nanoparticles (AgNPs), namely to assess meiotic maturation of oocytes, viability of follicular cells surrounding the oocyte, spontaneous contractile activity of the myometrium and pre-and postimplantation mortality of embryos.

Methods: Research (two series) has been done on white laboratory mice (8 weeks, 16-18 g). AgNPs are spherical nanoparticles of $30 \mathrm{~nm}(8 \mathrm{mg} / \mathrm{ml}$ for metal) diluted in water for injection. Method of treatment: intravenous. Two doses $(2 \mathrm{mg} / \mathrm{kg}$ and $4 \mathrm{mg} / \mathrm{kg}$ ) have been investigated. Frequency of treatment: one time per day with each dose of 1,5 and 10 times ( $\mathrm{n}=10$ animals in each group). Material for the study (ovaries, uterus) were taken the day after the last AgNPs injection.

Results: Ten-time AgNPs treatment $(2 \mathrm{mg} / \mathrm{kg}$ and $4 \mathrm{mg} / \mathrm{kg}$ ) results in inhibition of oocytes meiotic maturation in mice; a single- and five-time AgNPs treatment $(2 \mathrm{mg} / \mathrm{kg}$ and $4 \mathrm{mg} / \mathrm{kg}$ ) increases the number of apoptotic cells, while the ten-time AgNPs treatment results in an increase of the apoptotic and necrotic follicular cells surrounding oocytes; for the five-and ten-time AgNPs treatment ( $4 \mathrm{mg} / \mathrm{kg}$ ) the index of contractility (IC) of the uterus increased; for the ten-time AgNPs treatment $(2 \mathrm{mg} / \mathrm{kg}$ and $4 \mathrm{mg} / \mathrm{kg})$ no differences in value of the embryonic mortality between control and study groups have been observed.

Conclusions: This study suggests that the development of nanomaterials should be safer and non-toxic and the potential reprotoxicity of AgNPs should be investigated more carefully.
\end{abstract}

Keywords: Embryos, Myometrium, Oocytes, Silver nanoparticles

\section{INTRODUCTION}

The unique desired physico-chemical properties of NPs, such as higher stability in the aquatic environment, decreased size and increased specific surface area and thus enhanced reactivity, which makes nanomaterials more efficient in industrial applications and at the same time make them more harmful for living organisms. ${ }^{1,2}$ 
The use of silver nanoparticles (AgNP) has increased very significantly in recent years, with a current total global production estimated at 500 tons per year. ${ }^{1}$

AgNPs has the metallic elemental composition. AgNPs do not initially contain oxygen, the surface of metallic AgNPs is oxidized under most environmental conditions (aerobic) and negatively charged hydroxo and oxo groups cause the negative surface charge of the particle. ${ }^{3}$ The AgNPs are soluble to some extent in aqueous media. Toxicity data of AgNPs on bacteria, aquatic organisms and eukaryotic cells in vitro have also been recently summarized by. ${ }^{4}$ Due to the toxicity values of Ag NPs varied greatly: 275-time for mammalian cells in vitro and 500-time for bacteria and increasing production volumes of NPs and growing likelihood of occupational and environmental exposure to nanomaterials, the work in science is currently on focused on assessing humane health and environmental risks of nanotechnology.

Studies that will assess the effect of different doses, the way the multiplicity of the introduction of various sizes AgNPs on reproduction using female animals gain topicality. Such studies will provide new data that will contribute to a fuller understanding of AgNPs mechanisms of action in the laboratory as well as the successful transition of silver nanotechnology into the clinics. Thus, the effect of AgNPs on mammalian cells and tissues requires further study.

The aim was to estimate the functional status of the female reproductive system in mice under condition of the intravenous treatment of silver nanoparticles (AgNPs), namely to assess meiotic maturation of oocytes, viability of follicular cells surrounding the oocyte, spontaneous contractile activity of the myometrium and pre-and post-implantation mortality of embryos.

\section{METHODS}

Research (two series) has been done on white laboratory mice ( 8 weeks, 16-18 g) in compliance with all requirements for work with laboratory animals (International European Convention for the Protection of Vertebrate Animals, Strasbourg, 1986). After the experiments, anesthetized animals were sacrificed by Nembutal and dislocation of the cervical vertebrae.

\section{Characterization}

Characterization of nanoparticles AgNPs-30 nm (concentration: $8 \mathrm{mg} / \mathrm{ml}$ for metal, shape: spherical, color: brown, reagents used for synthesis: silver nitrate (AgNO3), (BioXtra, >99\% (titration, Sigma-Aldrich); carbonate potassium (K2CO3) (99,995\% trace metals basis, Sigma-Aldrich); Tannin (ACS reagent, SigmaAldrich) synthesized at the Ovcharenko Institute of biocolloidal chemistry NAS of Ukraine according to the original protocol (by chemical condensation).

\section{First series}

AgNPs are spherical nanoparticles of $30 \mathrm{~nm}(8 \mathrm{mg} / \mathrm{ml}$ for metal) diluted in water for injection. Method of treatment: intravenous. Two doses $(2 \mathrm{mg} / \mathrm{kg}$ and 4 $\mathrm{mg} / \mathrm{kg}$ ) have been investigated. Frequency of treatment: one time per day with each dose of 1, 5 and 10 times $(n=$ 8 animals in each group). Control animals injected with saline. Material for the study (ovaries, uterus) was taken the day after the last AgNPs injection.

\section{Oocytes cultivation}

The oocytes have been isolated mechanically from the ovaries of mice in a non-enzymatic way (without cumulus cells and in cumulus-oocyte-cell complexes). The mice oocytes from one group were collected and distributed into separate chambers, 10-20 oocytes each. All control and experimental oocytes were cultured under the same conditions (a sterile box, cameras with $0.4 \mathrm{ml}$ culture medium DME and $15 \mathrm{mM}$ HEPES, Ca2+ concentration of $1.71 \mathrm{mM}$, temperature $37{ }^{\circ} \mathrm{C}$, duration 20 hours). Morphological study of oocytes was performed under a microscope MBS-10 after 2 hours of cultivation (\% of total): the oocytes which restored the meiotic maturation (BM) and were at metaphase I stage (germinal vesicle break-down), and after 20 hours were at metaphase II stage (completed by the first division of meiosis and formed the first polar body (PB)) and oocytes with atypical morphology (unevenly granulated cytoplasm and fragmentation characteristics of the latter) have been counted.

\section{Method color fluorescent dyes}

The estimation of apoptotic and necrotic death of follicular cells was performed by morphological characteristics using the method of in vivo dual-color fluorescent dye nucleic acids Hoechst 33342 and propidium iodide. Morphological studies were performed using a fluorescent microscope with water-immersion at $\mathrm{x} 85$. There has been used a video system sending the image from the microscope to the computer. The percentage of the living, apoptotic and necrotic cells has been determined by counting at least 400 cells.

\section{The method of phase-graphical analysis in the study of the contractile activity of the uterine myometrium}

To investigate the contractile activity of the ovarian (OD) and cervical (CD) uterine myometrium departments the method of phase-graphic analysis has been used (5). To characterize the spontaneous emission by quantity of the following parameters contractile activity was taken into consideration: amplitude of reduction $(\mathrm{mN})$, frequency of reduction (number per second), duration of contraction and relaxation (sec), speed reduction and relaxation (mN/second); index of contractility ("IC" index of contractility, was calculated as the product of Fmax on CVmax/RVmax, mN). 
Strips of uterine myometrium have been separated from the connective tissue under the microscope MBS-10 and transferred to Krebs solution $\left(4^{0} \mathrm{C}\right)$. To register isometric force of reduction agents and $\mathrm{CD}$ myometrium of the uterus, which was being cut off with the endometrium along the uterine horns (up to $10 \mathrm{~mm}$ and a width of less than $1 \mathrm{~mm}$ to 4 from one horn), transferred into the camera and fixed. The Krebs solution $\left(37^{\circ} \mathrm{C}, \mathrm{pH} 7,29\right)$ was used as perfusion solution in a camera. The force of isometric contractions was recorded using the high-speed recorder. Uniformity of preparation perfusion with washing solutions was provided by the peristaltic pump НП-1M.

\section{Second series}

There has been investigated the effect of AgNPs on preand post-implantation embryo mortality. The introduction of substances was performed daily for 10 days in each group of animals. Groups of animals: 1-control $(n=10), 2-$ AgNPs (2 mg/kg, $\mathrm{n}=10), 3-\operatorname{AgNPs}(4 \mathrm{mg} / \mathrm{kg}, \mathrm{n}=10)$.

\section{Fetal mortality in mice}

Female control and experimental groups crossed with intact males.

Counted: A- number of live embryos; B - number of seats of resorption (number of dead embryos); B-number of corpora lutea of pregnancy. Indicators of pre-and postimplantation death was calculated using the formula: ((B$\mathrm{A}+\mathrm{B}) / \mathrm{B}) \cdot 100 \%$ and $(\mathrm{B} /(\mathrm{A}+\mathrm{B})) \cdot 100 \%$.

\section{Statistical analysis}

For the statistical analysis of the results the software package Origin 8 Pro (OriginLab Corp., North., MA, USA) and spreadsheets Microsoft@Excel2003 have been used. Student's t test was performed for continuous variables. $\mathrm{P}<0.05$ was considered statistically significant. The statistical analysis of the research results conducted by using analysis of variance ANOVA followed by comparison of mean values between groups by NewmanColes test using the statistic program. ${ }^{6}$

\section{RESULTS}

\section{The effect of AgNPs on oocytes meiotic maturation}

Single and five-time treatments with AgNPs $(2 \mathrm{mg} / \mathrm{kg}$ and $4 \mathrm{mg} / \mathrm{kg}$ ) did not affect the resumpsion of meiosis (metaphase I) and the formation of the first polar body (metaphase II) in oocytes (Figure 1).

A ten-time treatment with $\operatorname{AgNPs}(2 \mathrm{mg} / \mathrm{kg}$ and $4 \mathrm{mg} \mathrm{kg}$ ) resulted in a decrease in a number of oocytes capable of forming the first polar body (metaphase II), respectively, to $36,78 \pm 2,83 \%$ at $56,93 \pm 3,84 \%$ in controls ( $<<0,01, n$ $=8$ ) and $28,02 \pm 3,05 \%$ at $56,63 \pm 4,24 \%$ in controls (p $<0,01, \mathrm{n}=8)$.
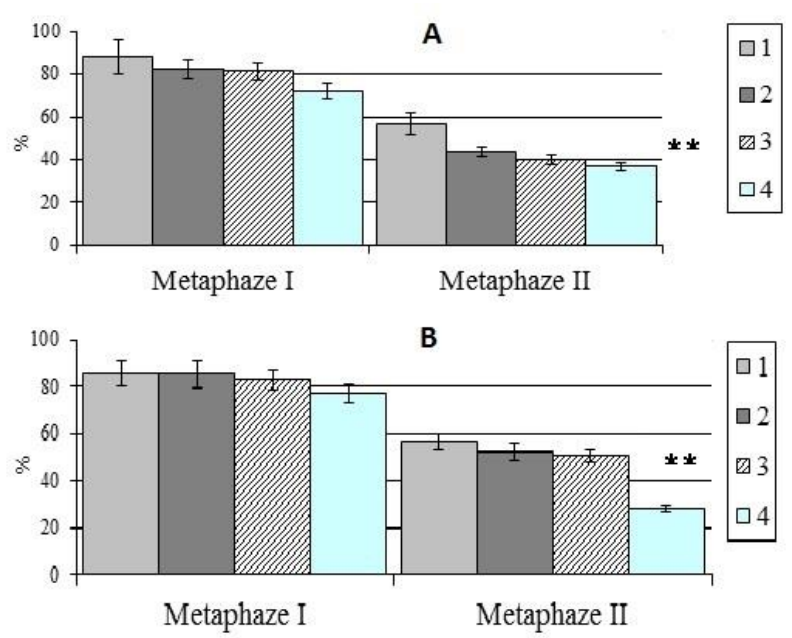

Note: groups of animals: A-AgNPs (2 мг/кг), B-AgNPs (4 мг/кг), 1-control; 2-single AgNPs; 3-five-fold AgNPs; 4-tenfold AgNPs. **- $\mathrm{P}<0.01$-probability differences in the average group data with respect to these variables in the control group animals.

Figure 1: The effect of the AgNPs treatment on oocyte meiotic maturation in mice $(n=8)$.

Thus, the treatment with a ten-fold AgNPs $(2 \mathrm{mg} / \mathrm{kg}$ and $4 \mathrm{mg} / \mathrm{kg}$ ) leads to inhibition of oocyte meiotic maturation in mice.

Table 1. Number of follicular cells surrounding oocytes (living cells with morphological features of apoptotic and necrotic death) under the AgNPs (2 mg/kg and $4 \mathrm{mg} / \mathrm{kg})$ treatment $(\mathrm{M} \pm \mathrm{SE})$.

\begin{tabular}{|lllll|}
\hline Dose & Groups of animals & Living cells, $\%$ & A poptotic cells, \% & Necrotic cells, \% \\
\hline \multirow{2}{*}{$2 \mathrm{mg} / \mathrm{kg}$} & Control & $84,0 \pm 3,37$ & $15,29 \pm 3,45$ & $0,71 \pm 0,76$ \\
& Single AgNPs & $70,57 \pm 2,37^{*}$ & $28,0 \pm 3,11^{*}$ & $1,43 \pm 0,79$ \\
& Five-time AgNPs & $66,20 \pm 1,64^{*}$ & $32,4 \pm 1,14^{* *}$ & $1,40 \pm 1,14$ \\
\cline { 2 - 5 } & Ten-time AgNPs & $62,80 \pm 1,64^{* *}$ & $33,40 \pm 0,89 * *$ & $3,80 \pm 0,84^{*}$ \\
\hline \multirow{3}{*}{$\mathrm{mg} / \mathrm{kg}$} & Control & $79,33 \pm 1,22$ & $19,0 \pm 0,89$ & $1,67 \pm 0,82$ \\
& Single AgNPs & $70,0 \pm 1,0^{*}$ & $28,20 \pm 1,48^{*}$ & $1,80 \pm 0,84$ \\
& Five-time AgNPs & $69,80 \pm 1,64^{*}$ & $28,00 \pm 2,35^{*}$ & $2,20 \pm 1,30$ \\
\hline
\end{tabular}

Notes: $*$-p $<0.05$; **-P $<0.01$-probability differences in the average group data with respect to these variables in the control group of animals $(\mathrm{n}=8)$. 


\section{Effect of AgNPs on apoptotic and necrotic death of follicular cells}

The data on the number of follicular cells surrounding oocytes (living cells with morphological features of apoptotic and necrotic death) under the AgNPs $(2 \mathrm{mg} / \mathrm{kg}$ and $4 \mathrm{mg} / \mathrm{kg}$ ) treatment are presented in Table 1 .

Treatment with AgNPs ( $2 \mathrm{mg} / \mathrm{kg}$ and $4 \mathrm{mg} / \mathrm{kg}$ ) is likely to reduce the number of living cells surrounding follicular oocytes.

Thus, one-time and five-times AgNPs $(2 \mathrm{mg} / \mathrm{kg}$ and 4 $\mathrm{mg} / \mathrm{kg}$ ) treatment increased the number of apoptotic cells, while the ten-times treatment increased the number apoptotic and necrotic cells surrounding follicular oocytes.

\section{Effect of AgNPs on the contractility of ovarian and cervical miometrium departments in mice}

A single treatment with AgNPs (2 mg/kg) caused no statistically significant differences in the values of the studied parameters (amplitude, IC, T, CVmax, RVmax and F) in OD and CV contractility (Figure 2). A five-time AgNPs (2 mg/kg) treatment caused in OD 1) a significant increase of values: IC to $3,12 \pm 0,58 \mathrm{mN}$ at $1,97 \pm 0,52$ $\mathrm{mN}$ in controls $(\mathrm{p}<0.05), \mathrm{T}$ to $6,13 \pm 0,62 \mathrm{~s}$ at $11,5 \pm 1,05$ $\mathrm{s}$ in controls $(\mathrm{p}<0.05)$, the value of the amplitude of the frequency and not statistically different from those in control; in CD it caused 2) an increase of the value to $3,98 \pm 1,01 \mathrm{mN}$ at 2,53 $\pm 0,39 \mathrm{mN}$ in controls ( $\mathrm{p}<0.05$ ), changes of amplitude, $\mathrm{T}$ and $\mathrm{F}$ were not statistically significant (Figure 2).

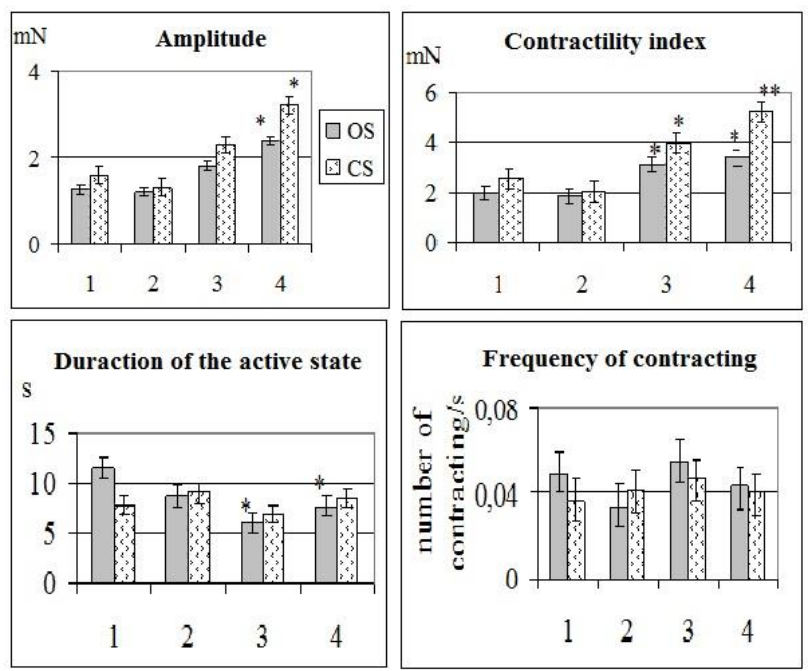

Note: groups of animals: 1-control; 2-single AgNP $(2 \mathrm{mg} / \mathrm{kg})$; 3-five-time AgNP (2 mg/kg); 4-ten-time AgNP (2 mg kg). *-P $<0.05 ; * *$-P $<0.01$-probability differences in average group data with respect to the same variables in the control group animals.

Figure 2: The effect of AgNP (2 mg/kg) on the contractility of ovarian and cervical uterine myometrium departments $(n=8)$.
A ten-time AgNPs (2 mg/kg) treatment caused in OD 1) a change in values of the following parameters: an amplitude increase to $2,43 \pm 0,59 \mathrm{mN}$ at $1,25 \pm 0,33 \mathrm{mN}$ in controls ( $\mathrm{p}<0.05)$ and IC to $3,48 \pm 0,82 \mathrm{mN}$ at $1,97 \pm$ $0,52 \mathrm{mN}$ in controls ( $\mathrm{p}<0.05$ ), a decrease in $\mathrm{T}$ to $7,75 \pm$ $0,81 \mathrm{~s}$ at $11,5 \pm 1,05 \mathrm{~s}$ in control $(\mathrm{p}<0.05) ; 2)$ an increase in the CV of variables: amplitude to $3,22 \pm 0,82 \mathrm{mN}$ at $1,58 \pm 0,24 \mathrm{mN}$ in controls ( $\mathrm{p}<0.05$ ), IS to $5,22 \pm 0,47$ $\mathrm{mN}$ at $2,53 \pm 0,39 \mathrm{mN}$ in controls $(\mathrm{p}<0.01)$, the values of $\mathrm{T}$ and $\mathrm{F}$ were not statistically different from the control data (see Figure 2).

Thus, the treatment with AgNPs (2 mg/ $/ \mathrm{kg}$ ) causes significant changes in the parameters of uterine contractility: at five-time treatment IC and $\mathrm{T}$ increase, at ten-time treatment amplitude and IC increase, while $\mathrm{T}$ decreases.

A single treatment with AgNPs (4 mg/kg) caused no statistically significant differences in the values of the studied parameters (amplitude, IC, T, CVmax, RVmax and $\mathrm{F}$ ) in contractility of OD and CD (Figure 3).

A five-time AgNPs (4 mg/kg) treatment caused in OD 1) an increase of amplitude to 2,27 $\pm 0,46$ at $1,30 \pm 0,15 \mathrm{mN}$ ( $\mathrm{p}<0.05$ ), IC to $4,79 \pm 1,22$ at $1,90 \pm 0,17 \mathrm{mN}$ in controls ( $\mathrm{p}<0.01$ ); in $\mathrm{CV} 2$ ) an increase of IC to $3,45 \pm 0,57 \mathrm{mN}$ at $2,56 \pm 0,37 \mathrm{mN}$ in controls $(\mathrm{p}<0.05)$. The change in value of other parameters were not statistically significant (Figure 3).

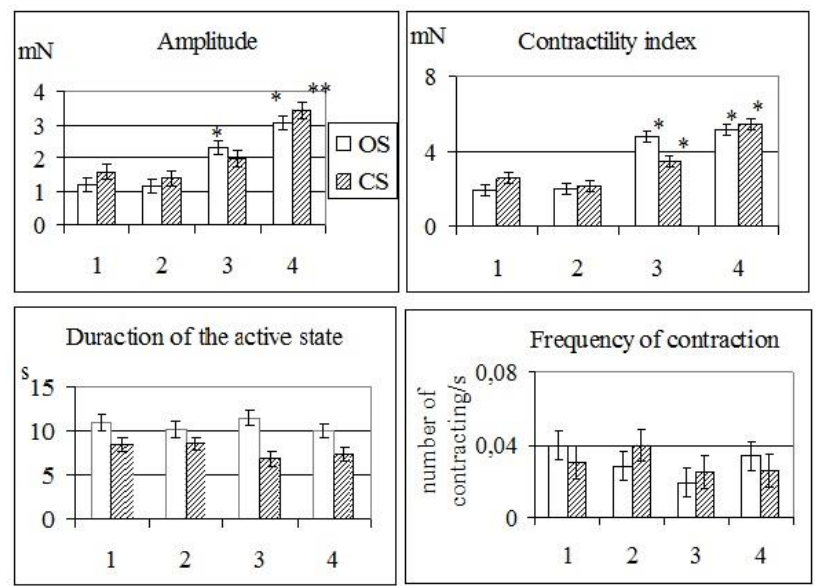

Note: groups of animals: control; 2-single AgNPs (4 mg/kg); 3five-time AgNPs (4 mg/kg); 4-ten-time AgNPs (4 mg/kg). *-P $<0.05$; **-P <0.01-probability differences in average group data with respect to the same variables in the control group animals.

Figure 3. The influence of the AgNPs (4 mg kg) treatment on the contractility of ovarian and cervical departments $(n=8)$.

A ten-time AgNPs (4 mg/kg) treatment caused in OD 1) an increase in the following values: amplitude up to 3,05 $\pm 0,84 \mathrm{mN}$ at $1,30 \pm 0,15 \mathrm{mN}$ in controls $(\mathrm{p}<0.05)$ and IC $5,21 \mathrm{mN} \pm 1,16$ at $1,90 \pm 0,17 \mathrm{mN}$ in controls (p $<0.05$ ), the values of CVmax, RVmax, $\mathrm{T}$ and $\mathrm{F}$ were not statistically different from the values of the data in the 
control group; in CV 2) an increase of the following amplitude to $3,42 \pm 1,10 \mathrm{mN}$ at $1,56 \pm 0,58 \mathrm{mN}$ and IC to $5,45 \pm 1,51 \mathrm{mN}$ at $2,56 \pm 0,37 \mathrm{mN}$ in control $(\mathrm{p}<0.05)$ and $\mathrm{RVmax}$ to $0,32 \pm 0,06 \mathrm{mN} / \mathrm{s}$ at $0,18 \pm 0,03 \mathrm{mN} / \mathrm{s}$ (p $<0.05$ ), the value CVmax, T and FM were not statistically different from the data in the control group (see Figure $3)$.
Thus, five-time and ten-time treatments AgNPs (4 mg/kg) change such uterine contractility parameters: an increase in amplitude and IC.

Effect of AgNPs on fetal mortality in mice. Data of preand post-implantation mortality in mice are presented in Table 2.

Table 2. Pre-and post-implantation embryonic mortality in mice after treatment with AgNPs (2 mg/kg and 4 $\mathrm{mg} / \mathrm{kg})(\mathrm{M} \pm \mathrm{SE})$.

\begin{tabular}{|llll|}
\hline Embryonic mortality & Control & Ten-time AgNPs $(\mathbf{2}$ mg/kg) & Ten-time AgNPs $(4 \mathrm{mg} / \mathrm{kg})$ \\
\hline Pre-implantation & $2,76 \pm 0,74$ & $3,25 \pm 1,36$ & $4,34 \pm 2,22$ \\
\hline Post-implantation & $1,38 \pm 0,37$ & $1,51 \pm 0,68$ & $2,17 \pm 1,12$ \\
\hline
\end{tabular}

Thus, a ten-time AgNPs treatment ( $2 \mathrm{mg} / \mathrm{kg}$ and $4 \mathrm{mg} / \mathrm{kg}$ ) is not likely to cause differences in values of the index embryonic mortality between control and study groups.

\section{DISCUSSION}

Intravenous (IV) treatment (injection) of silver can still provide valuable information on the processes taking place in-vivo AgNPs which has to overcome the main barriers (like skin, lungs, gastrointestinal tract) and in terms of putting it into circulation a clinical purpose (for example: dressings materials, intravascular medical devices for diagnosis, to drug delivery). Since this study was not designed to simulate scenarios of human exposure to avoid the limited systemic exposure due to the existence of cellular barriers in the skin, gastrointestinal tract and lungs, in order to assess the potential systemic toxicity, we used intravenous (IV) treatment of AgNPs-nanoparticles $30 \mathrm{~nm}$ (shape: spherical, color: brown).

Since a dose of $10 \mathrm{mg} / \mathrm{kg}$ body weight in mice is equivalent to the human dose of $0.81 \mathrm{mg} / \mathrm{kg}$ body weight, which corresponds to about $50 \mathrm{mg}$ for a person of $60 \mathrm{~kg}$, according to the principles of conversion of doses animals to humans. ${ }^{6}$ The doses of $2 \mathrm{mg} / \mathrm{kg}$ and $4 \mathrm{mg} / \mathrm{kg}$ body weight were chosen because they are in the range of doses used in previous studies IV without causing significant side effects in animals. ${ }^{7-10}$

There are data about intravenous (IV) treatment of AgNPs. ${ }^{11,12}$ So, silver was found in the main organs after AgNPs administration done in different ways. ${ }^{13,14}$ There is also evidence of distribution of silver in tissues after oral administration in rats. ${ }^{13}$

The highest concentrations of silver regardless of their coverage and regarding all sizes of particles were found in spleen and liver, and lungs, kidneys and brain 24 hours after IV. The largest share of silver that reaches the blood is filtered by the liver and excreted through the gall. ${ }^{7,9,15}$ The scheme of silver treatment has been described depending on the size in the liver and it has been suggested that absorption of silver by the Kupffer cells hardly occurs after administration of $100 \mathrm{~nm}$ AgNPs, while the introduction of $10 \mathrm{~nm}$ and $40 \mathrm{~nm}$ AgNPs led to the absorption of silver both endothelial cells and hepatocytes, in addition to the Kupffer cells. Only occasionally, silver was identified in gallbladder of 10 nm AgNP-treated mice (within the epithelial cells of the gallbladder and endothelial cells of blood vessels). In lungs silver was found in the alveolar walls, capillaries, and interstitial tissue. ${ }^{15}$

In literature, there are data about the impact of nanoparticles on oocytes. ${ }^{16-18}$ There have been published data about the effect nanoparticles of gold, silver, and gold-silver alloy, which were covered with bovine serum albumin (BSA) on in vitro cumulus-oocytes-cellcomplexes of pigs. ${ }^{18}$ Meiotic maturation of oocytes was assessed after 46 hours of cultivation in vitro in the presence of different types of nanoparticles and silver nitrate in the environment during all the time. Maturation in this case is defined as the percentage of oocytes that reflect the metaphase plate and the formed polar body (the second meiotic division) in 350 oocytes per group. The concentration of nanoparticles was $10 \mathrm{mg} / \mathrm{ml}$, and all particles were conjugated to bovine serum albumin (BSA). ${ }^{17}$

In the presented research, a single AgNPs treatment (2 $\mathrm{mg} / \mathrm{kg}$ ) causes a statistical decrease in the number of living cells of follicular environment by 1,19 times and an increase in apoptosis in follicular cells in 1.83 times. A single AgNPs treatment $(4 \mathrm{mg} / \mathrm{kg}$ ) causes a decrease in the number of living cells from follicular environment of oocytes in 1.13 times, the increase of cells with the signs of apoptosis by 1.48 times.

A five-time AgNPs treatment $(2 \mathrm{mg} / \mathrm{kg}$ ) causes an increase of apoptotic cells by 2.12 times, while statistically significant differences in the oocytes meiotic maturation have not been observed. A five-time AgNPs treatment $(4 \mathrm{mg} \mathrm{kg})$ caused a decrease in the number of living cells from follicular environment of oocytes in 1.14 times and an increase in apoptosis in follicular cells 
in 1.47 times, while statistically significant differences in the oocytes meiotic maturation have not been observed.

A ten-time AgNPs $(2 \mathrm{mg} / \mathrm{kg})$ treatment caused a statistically significant decrease in the number of oocytes capable of forming the first polar body (metaphase II) in 1,55 times (by $64.61 \%$ ) as compared to control subject; a five-time AgNPs treatment $(4 \mathrm{mg} / \mathrm{kg}$ ) caused a decrease in the number of oocytes capable of forming the first polar body (metaphase II) in 2.02 times (by 49,48\%).

A five-time AgNPs a treatment ( $2 \mathrm{mg} / \mathrm{kg}$ ) caused in OD a significant increase in IC values by $58.4 \%$ and a decrease of $\mathrm{T}$ at $46.7 \%$. In $\mathrm{CV}$, there has been an increased IC by $57.3 \%$ ( $p<0.05)$. The change in the amplitude and the $\mathrm{F}$ were not statistically significant.

In OD, the ten-time AgNPs (2 mg/kg) treatment caused increasing amplitudes in 1.9 times, an increase of IC in 1.8 times and a decrease of $\mathrm{T}$ in 1.5 times. In $\mathrm{CD}$, the amplitude increased in 2.0 times, while IC increased in 2.1 times, the value of $\mathrm{T}$ and FM was not statistically different from the control data. In OD, the increase of the amplitude in 1.7 times and of IC in 2.5 times has been observed. In CD, an increase of IC in 1.4 times in comparison with control has been observed. The changes in the value of other parameters were not statistically significant.

A ten-time AgNPs (4 mg/kg) treatment caused an increase of amplitude in 2.4 times and an increase of IC in 2.7 times in OD. Such values as $\mathrm{CV}_{\max }, \mathrm{RV}_{\max }$, $\mathrm{T}$ and FM were not statistically different from the values of such data in the control group. In $\mathrm{CD}$, there has been an increase of amplitudes in 2.2 times and of IC in 2.1 times, the values of $\mathrm{CV}_{\max }, \mathrm{T}$ and $\mathrm{F}$ were not statistically different from the values of such data in the control group.

The embryo development under conditions of nanoparticle treatment is in the focus of attention of scientists. It has been established that in vitro silver nanoparticles 50 microM inhibited pre-implantation development of mice embryos. ${ }^{19}$ There are also data that silver nanoparticles do not have any effect on mice embryos. $^{20}$

The differences in body weight, food consumption, weight body index pregnancy, fetal death, fetal weight and placental sex ratio, morphological changes between groups have been evaluated. It has been established that the repeated oral administration of AgNPs during pregnancy causes oxidative stress in the liver tissue at $\geq 100 \mathrm{mg} / \mathrm{kg} /$ day, but does not cause changes in the development of embryo and fetus under conditions of administration of doses up to $1000 \mathrm{mg} / \mathrm{kg} /$ day. ${ }^{21}$

The rate of blastocysts after microinjection of nanoparticles in 2-cell stage mouse embryos (nanoparticles of gold, 67.3\% silver nanoparticles: $61.5 \%$ false, $66.2 \%$, processing control: $79.4 \%$ ) did not differ in experimental and control groups. Using polymerase chain reaction (PCR) in a real-time analysis of six major ontogenetic genes (CVC, BCL2L2, TP53, OCT4, NANOG, Dnmt3a) no effect of nanoparticles in gene expression of blastocyst has been registered. Unlike silver nanoparticles, the influence of comparable concentrations of $\mathrm{Ag}+$ ions resulted in the immediate arrest of development of the embryo. ${ }^{20}$

We obtained data that rates of embryonic mortality had not changed the conditions a ten-time treatment AgNPs ( $2 \mathrm{mg} / \mathrm{kg}$ and $4 \mathrm{mg} / \mathrm{kg}$ ); our data are consistent with the previous data, confirming the statement that embryos may have potential for the deployment of compensatory mechanisms of action under conditions of silver administration at doses lower than those causing obvious toxicity. ${ }^{18,20}$

It is also one more proof to support the hypothesis that the AgNPs toxicity is primarily linked to $\mathrm{Ag}+$ bioavailability. It is important to stress that our data suggest that oocytes in mammals have the potential for the deployment of compensatory mechanisms of action under conditions of $\mathrm{Ag}+$ administration at doses lower than those causing obvious toxicity.

Probably, the differential toxicity of nanosilver may be connected with different coatings that are often applied to the AgNPs surface to achieve a stabilizing effect (22). In addition, all the characteristics of NPs need to be considered: size, shape, crystalline structure, aggregation, chemical composition, surface properties (surface charge, surface area), the solubility, and porosity.

Further studies are needed for the elucidation of mechanisms of AgNPs influence on germ and somatic cells administering AgNPs of different sizes and coatings.

Despite the fact that the toxicity appears to be caused by oxidation and inflammation, it is still not entirely clear what is responsible for the toxic effects of silver: whether this is the form of nanoparticles or whether this is silver ions alone during oxidation of the metal. ${ }^{23,24,4}$

There is evidence that AgNPs influence the induction of oxidative damage, change the regulation of enzymes, which are responsible for removing free radicals, change regulation of genes expression, which are involved in apoptosis and dis-regulation of cellular structures involved in storage, detoxification and metabolism of metals in various organs..$^{25,26}$

Silver ions were equally toxic as both metal particles containing $80 \%$ silver and pure AgNP indicating that at least their toxic potential was similar. ${ }^{17}$

Our results confirm that the in vitro maturation of oocytes and evaluation of pre- and post-implantation embryos are sensitive systems for research related to nano-toxicology 
in which subtle effects can be visualized. Using such test systems in the future will contribute to deepening the understanding of the possible effects of nanoparticles on female reproduction. Also, future research could lead to the development of clear specifications of nanoparticles (from the dose size) under the appropriate biological conditions.

Despite the fact that existing literature data give grounds to confirm that despite the promising potential for the use of AgNPsin medicine as well as the conducted toxicological studies AgNPs, it is still difficult to make univocal conclusion about the extent of their impact on the human body. At present, little is known about the specific effects of the AgNPsimpact on the environment and it is practically impossible to reliably estimate the environmental risks associated with their production and use.

\section{CONCLUSION}

These data confirm that the oocytes and embryos make a sensitive system for studies involving nanotoxicology, which can be visualized by thin-effects. Using this test system in the future will contribute to a deeper understanding of the possible effects of nanoparticles on female reproduction.

Studies that will assess the effect of different doses, the way the multiplicity of the introduction of various sizes AgNPs on reproduction using female animals gain topicality. Such studies will provide new data that will contribute to a fuller understanding of AgNPs mechanisms of action in the laboratory as well a successful transition of silver nanotechnology into the clinic.

\section{ACKNOWLEDGEMENTS}

Authors would like to thank Bogomoletz Instytute of Physiology and Ovcharenko Institute of Biocolloidal Chemistry for the financial support of our study.

Funding: The work was done in 2016 under the scientific program of the Department of Immunophysiology O.O.Bogomoletz Instytute of Physiology NAS of Ukraine: "The study of molecular genetics and immunopathological mechanisms of functional disorders of the female reproductive system and the possibility of correction." State registration number of topics 0112 U008233

Conflict of interest: None declared

Ethical approval: The study was approved by $O$. $O$. Bogomoletz Instytute of Physiology Ethical Committee, Kyiv, Ukraine

\section{REFERENCES}

1. Fabrega J, Luoma S, Tyler C, Galloway T, Lead J. Silver nanoparticles: behaviour and effects in the aquatic environment. Environ Int. 2011;37(2):51731.

2. Nel A, Xia T, Mädler L, Li N. Toxic potential of materials at the nanolevel. Science. 2006;311(5761): 622-7.

3. Levard C, Hotze E, Lowry G, Brown G. Environmental transformations of silver nanoparticles: impact on stability and toxicity. Environ Sci Technol. 2012;46(13):6900-14.

4. Chernousova S, Epple M. Silver as antibacterial agent: ion, nanoparticle, and metal. Angew Chem Int Ed Engl. 2013;52(6):1636-53.

5. Gullam J, Blanks A, Thornton S, Shmygol A. Phaseplot analysis of the oxytocin effect on human myometrial contractility. Eur J Obstet Gynecol Reprod Biol. 2009;144(1):20-4.

6. Reagan-Shaw S, Nihal M, Ahmad N. Dose translation from animal to human studies revisited. FASEB J. 2008;22(3):659-61.

7. Park K, Park E, Chun I, Choi K, Lee S, Yoon J, et al. Bioavailability and toxicokinetics of citrate-coated silver nanoparticles in rats. Arch Pharm Res. 2011; 34(1):153-8.

8. Dziendzikowska K, Gromadzka-Ostrowska J, Lankoff A, Oczkowski M, Krawczyńska A, Chwastowska J, et al. Time-dependent biodistribution and excretion of silver nanoparticles in male Wistar rats. J Appl Toxicol. 2012;32(11): 920-8.

9. Xue Y, Zhang S, Huang Y, Zhang T, Liu X, Hu Y, et al. Acute toxic effects and gender-related biokinetics of silver nanoparticles following an intravenous injection in mice. J Appl Toxicol. 2012;32(11):8909.

10. De Jong W, Van Der Ven L, Sleijffers A, Park M, Jansen E, Van Loveren $\mathrm{H}$, et al. Systemic and immunotoxicity of silver nanoparticles in an intravenous 28 days repeated dose toxicity study in rats. Biomaterials. 2013;34(33):8333-43.

11. Rigo C, Ferroni L, Tocco I, Roman M, Munivrana I, Gardin C, et al. Active silver nanoparticles for wound healing. Int J Mol Sci. 2013;14(3):4817-40.

12. Wei L, Lu J, Xu H, Patel A, Chen Z, Chen G. Silver nanoparticles: synthesis, properties, and therapeutic applications. Drug Discov Today. 2015;20(5):595601.

13. van der Zande M, Vandebriel R, Van Doren E, Kramer E, Herrera Rivera Z, Serrano-Rojero C, et al. Distribution, elimination, and toxicity of silver nanoparticles and silver ions in rats after 28-day oral exposure. ACS Nano. 2012;6(8):7427-42.

14. Kwon J, Minai-Tehrani A, Hwang S, Kim J, Shin J, $\mathrm{Yu} \mathrm{K}$, et al. Acute pulmonary toxicity and body distribution of inhaled metallic silver nanoparticles. Toxicol Res. 2012;28(1):25-31.

15. Recordati C, De Maglie M, Bianchessi S, Argentiere $\mathrm{S}$, Cella C, Mattiello S, et al. Tissue distribution and acute toxicity of silver after single intravenous administration in mice: nano-specific and size- 
dependent effects. Part Fibre Toxicol. 2016; 29(13):12.

16. Johnston H, Hutchison G, Christensen F, Peters S, Hankin S, Stone V. A review of the in vivo and in vitro toxicity of silver and gold particulates: particle attributes and biological mechanisms responsible for the observed toxicity. Crit Rev Toxicol. 2010;40(4): 328-46.

17. Tiedemann D, Taylor U, Rehbock C, Jakobi J, Klein $\mathrm{S}$, Kues W, et al. Reprotoxicity of gold, silver, and gold-silver alloy nanoparticles on mammalian gametes. Analyst. 2014;139(5):931-42.

18. Taylor U, Tiedemann D, Rehbock C, Kues W, Barcikowski S, Rath D. Influence of gold, silver and gold-silver alloy nanoparticles on germ cell function and embryo development. Beilstein J Nanotechnol. 2015;5(6):651-64.

19. Li P, Kuo T, Chang J, Yeh J, Chan W. Induction of cytotoxicity and apoptosis in mouse blastocysts by silver nanoparticles. Toxicol Lett. 2010;197(2):82-7.

20. Taylor U, Garrels W, Barchanski A, Peterson S, Sajti L, Lucas-Hahn A, et al. Injection of ligand-free gold and silver nanoparticles into murine embryos does not impact pre-implantation development. Beilstein J Nanotechnol. 2014;21(5):677-88.

21. $\mathrm{Yu}$ W, Son J, Lee J, Kim S, Lee I, Baek H, et al. Effects of silver nanoparticles on pregnant dams and embryo-fetal development in rats. Nanotoxicology. 2014;8(1):85-91.

22. Durán N, Durán M, de Jesus M, Seabra A, Fávaro W, Nakazato G. Silver nanoparticles: A new view on mechanistic aspects on antimicrobial activity. Nanomedicine. 2016;12(3):789-99.

23. Hsin Y, Chen C, Huang S, Shih T, Lai P, Chueh P. The apoptotic effect of nanosilver is mediated by a ROS- and JNK-dependent mechanism involving the mitochondrial pathway in NIH3T3 cells. Toxicol Lett. 2008;179(3):130-9.

24. Laban G, Nies L, Turco R, Bickham J, Sepúlveda M. The effects of silver nanoparticles on fathead minnow (Pimephales promelas) embryos. Ecotoxicology. 2010;19(1):185-95.

25. Choi J, Kim S, Ahn J, Youn P, Kang J, Park K, et al. Induction of oxidative stress and apoptosis by silver nanoparticles in the liver of adult zebrafish. Aquat Toxicol. 2010;100(2):151-9.

26. Maillard J, Hartemann P. Silver as an antimicrobial: facts and gaps in knowledge. Crit Rev Microbiol. 2013;39(4):373-83.

Cite this article as: Lytvynenko AP, Rieznichenko LS, Sribna VA, Stupchuk MI, Grushka NG, Shepel AA, et al. Functional status of reproductive system under treatment of silver nanoparticles in female mice. Int J Reprod Contracept Obstet Gynecol 2017;6:1713-20. 